\title{
A Robust Indicator for Promoting Circular Economy through Recycling
}

\author{
Francesco Di Maio, Peter Carlo Rem \\ Delft University of Technology, Delft, The Netherlands \\ Email: f.dimaio@tudelft.nl
}

Received 25 August 2015; accepted 6 October 2015; published 9 October 2015

Copyright (C) 2015 by authors and Scientific Research Publishing Inc.

This work is licensed under the Creative Commons Attribution International License (CC BY). http://creativecommons.org/licenses/by/4.0/

(c) (i) Open Access

\section{Abstract}

In order to move towards a more sustainable development, it is necessary not only to minimize the use of materials in the design stage and to find new materials as alternatives to nonrenewable ones (e.g. optical fiber instead of copper, biopolymers instead of polymers from oil) but also to reclaim as much as possible material value through effective recycling. To this extent, recycling can play a key role in multiple dimensions, while providing new business opportunities for innovative companies, having positive impacts on the society and the environment and fostering an effective circular economy as well. Because of the advanced waste management infrastructures available in developed countries, it is possible to achieve an almost complete collection of solid wastes into a variety of controlled bulk material flows. However, the picture for the follow-up step, the recycling of raw materials such as steel, non-ferrous metals, polymers and glass from these flows, is less positive. Materials value recovered from waste represents a very small fraction of European GDP. The fundamental issue is that policymakers still lack an effective key performance indicator for stimulating the recycling industry. Therefore although recycling plays an important role in the circular economy perspective, it is necessary to radically change the metric used so far to compute the recycling rate. Nowadays, the recycling rate is computed measuring the amount of material entering the recycling facilities. This approach has brought about an inaccurate and somehow misleading indicator (the recycling rate) which contributed to wrong decision making and to poor innovation in the industry. The new approach proposed in this paper considers the use of a Circular Economy Index (CEI) as the ratio of the material value produced by the recycler (market value) by the intrinsic material value ${ }^{1}$ entering the recycling facility. It is argued that this index is related to strategic, economic and environmental aspects of recycling and it has very important implications as decision making tool. To compute the CEI it is necessary to know detailed information of the components and materials contained in each end of life (EOL) product entering the recycling facilities and how they end up in the recycled raw materials. Therefore an accurate accounting of materials (with standards if available), mass, chemical composition and smallest dimension (e.g. a screw, a plastic foil) is proposed.

\footnotetext{
${ }^{1}$ The present market value of all materials that would be needed to re-produce the EoL products that make up the waste.
} 


\section{Keywords}

\section{Recycling, Recycling Rate, Innovation, Policy, Resource Efficiency, Indicators}

\section{Introduction}

The linear take-make-dispose economic model relies on large quantities of easily accessible resources, and as such is increasingly unfit for the reality in which it operates [1]. A reduction of resources consumed per unit of manufacturing output can only slowdown the depletion of those resources as it cannot modify the finite nature of their stocks. Demand and competition for limited resources increase price volatility, cause environmental degradation and threaten the competitiveness of countries. That is why the European Union as well as other countries worldwide are striving to move toward a circular economy model [2].

In order to move towards a more sustainable development and at the same time create opportunities for economic growth, a fundamental transformation in producer and consumer behavior is needed. It is crucial to increase the resource efficiency of production optimizing the use of materials in the design stage and to find new materials as alternatives to nonrenewable ones (e.g. optical fiber instead of copper, biopolymers instead of polymers from oil). In many countries, it is also necessary to improve the resource efficiency of collection. However, what is most urgent is to minimize the amount of materials which are currently disposed of, through effective recycling (cf. Figure 1).

The waste management infrastructure of Europe is already well developed so that it achieves an almost complete collection of solid wastes into a variety of controlled bulk material flows [3]. The picture for the follow-up step, the recycling of raw materials such as steel, non-ferrous metals, polymers and glass from these flows, is less positive. Materials value recovered from waste represents less than $0.5 \%$ of European GDP, even at the most favorable of economic conditions (EEA report). In most EU countries, recycling provides only between 5\% and $15 \%$ in value of the raw materials used in manufacturing and construction [4]. The fundamental issue is that policymakers still lack an effective key performance indicator for stimulating the recycling industry.

Therefore although recycling is currently playing an important role in the circular economy perspective, it is necessary to radically change the metric used so far to compute the recycling rate. Nowadays the recycling rate is computed measuring the amount of material entering the recycling facilities. This approach has brought about an inaccurate and somehow misleading indicator (the recycling rate) which contributed to wrong decision making and to poor innovation in the industry [5] [6].

It is well known that material recycling is beneficial not only for the environment but also for the economy and the society at large. Every kilogram of recycled material can replace primary material and therefore displaces the activities that are needed to locate, mine and process it. All such activities use energy, release pollution and alter the landscape in ways that are perceived as a danger to the environment. Some raw materials (e.g. cobalt, copper, platinum, neodymium, etc.) involve also relevant social issues such as conflicts to access minerals, human rights violations, black market, etc. [7].

Because of the advanced waste management infrastructures available in developed countries, large amount of end-of-life (EoL) industrial and consumer products are available. Despite their potential value, these EoL products are still called waste residuals instead of "surface mines" waiting to be exploited [8]. However it is well es-

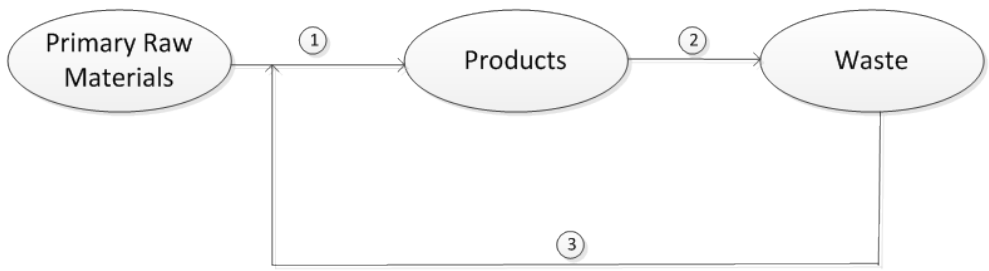

1. Resource efficiency of production

2. Resource efficiency of collection

3. Resource efficiency of recycling

Figure 1. Material flow and resource efficiencies. 
tablished that increasing the efficient use of resources creates economic value (at firm, national and European level) and that the production of secondary materials is inherently more labor-intensive and less energy intensive than the production of primary materials [4]-[9]. Thus it creates significantly more jobs and requires higher levels of skills, facilitating the entry of women into the labor [10].

\section{From a Linear to a Circular Economy}

Europe has the world's highest net imports of resources per person, and its open economy relies heavily on imported raw materials and energy. Secure access to resources has become an increasingly strategic economic issue, while possible negative social and environmental impacts on third countries constitute an additional concern [11]. In 2013, a total amount of 5.7 billion tonnes [12] of materials has been used by the EU economy to provide its citizens with the goods and services they needed. In terms of value, the above total amount accounts to about 400 bn euro ${ }^{2}$.

Considering that by 2050 the world population will hit 10 billion people, the increase in material use that would occur even at the current development levels and resource consumption patterns will reach about $180 \%$ of the 1990's level [13]. However economic development (in the sense of GDP increase) will take place as it is the main objective of governments in the developing as well as developed part of the world. Combining the effect of population growth and GDP increase in the developing countries results in a hefty increase of the consumption of natural resources (up to $800 \%$ of the 1990's value) [13].

Besides the implications of the fact that materials extracted from the earth and utilized for economic purposes are not literally "consumed" but become waste residuals that do not disappear and may cause environmental damage and result in unpaid social costs [14], experts have calculated that without a rethink of how materials are used in the current linear "take-make-dispose" economy, the virgin stocks of several key materials appear inadequate to sustain the modern "developed world" quality of life for all earth's peoples under contemporary technology [15]. Therefore it is necessary to move towards an industrial model that decouples economic growth from material input: The Circular Economy (CE). CE models maintain the added value in products for as long as possible and minimize waste. They keep resources within the economy when products no longer serve their functions so that materials can be used again and therefore generate more value. Thus circular business models create more value from each unit of resource than traditional linear models.

Although the CE approach contrasts with the mind-set embedded in most current industrial operations where even the terminology (value chain, supply chain, end user) expresses a linear view, several benefits may rise from the shift to the Circular Economy model and to a more resource-efficient path.

Since the early days of industrialization, companies mine and extract materials, use them to manufacture goods and sell the goods to customers (or end users) who dispose of them when they become obsolete or no longer useful. Some 65 billion tons of raw materials entered the economic system in 2010 and this figure is expected to grow to around 82 billion tons in 2020 [16].

The material saving potential arising from the transition to a CE model and to a more resource efficient path is estimated to 500 billion $€$ per year for the European industry [17]. The job creation potential of remanufacturing and recycling in Europe is estimated at one million [1]. From the strategic point of view the benefits of the CE approach arise from the reduced risk of supply disruption and price volatility as well as from the huge potential for innovation related to new technologies (needed to increase resource productivity, material substitution, waste management and recycling), improvements of the forward and reverse cycles (optimization of the supply chain and logistics) and business models.

\section{The Need of New Indexes}

Taking into account the facts outlined above, we do believe that it is necessary to stimulate recycling through proper legislation and effective financial incentives. To this extent we assume that the robust and intuitive CE index proposed in this paper can help society to achieve the social, environmental, economic and strategic goalsit pursues.

To assess the environmental impact of any product throughout its life cycle, Life Cycle Assessment (LCA) is currently used [18]. Although the LCA method provides good insights about the environmental burden of each

\footnotetext{
${ }^{2}$ The value of materials at the point where they are in their final chemical composition, but not yet manufactured as a part or component.
} 
product/industry, it is not always cost effective because a detailed LCA requires large amount of data and therefore it is time consuming [18]-[20].

Moreover the LCA studies provide information only on the environmental domain of sustainability, neglecting the economic and social ones which should be addressed simultaneously [19] [21] [22].

Also material flow accounting and analysis (MFA) is at present used to assess environmental as well as economic and other policies [23].To address in particular the economic policies, a methodological guide for economy-wide MFA (EW-MFA) has been developed by the Statistical Office of the European Commission (EUROSTAT) in 2001 [12]. However expert experiences in reviewing progress of these indicators toward numerical targets, have revealed several practical problems with the calculated indicators. For instance the time-lag in the availability of data and the fact that EW-MFA indicators are inherently macroscopic so that it is difficult to observe the direct effects of individual efforts to achieve CE [23].

\section{The Driving Forces for the New Approach}

The Circular Economy Index (CEI) proposed in this article uses a different approach. It aims at introducing the economic value of the materials embedded in consumers products as the property to be measured and accounted. It is argued that this index is related to a wide range of strategic, economic, social and environmental aspects of recycling and is therefore a proper instrument for decision making.

An important aspect of the CEI is that it does need data that are available in the companies' financial reports and in the bureaus of statistics so that the analysis of the performance is possible at firm as well as sector level (local, national or European).

Because the CEI intuitively represents the effectiveness of recycling firms at extracting value from the processed materials, it represents a decision making tool which will help management and policy makers to steer decision towards value creation and technological innovation.

A successful indicator for policymaking is always a compromise between the need for conceptual simplicity, the cost of evaluation and the degree to which the indicator is in parallel with current policy targets. Mass recycling rates, for example, are vastly popular for their conceptual simplicity and the relative ease of computing it for specific (categories of) EoL products (cf. Figure 2). Yet, the relation between the indicator and primary economic and environmental policy targets such as job creation and reduction of greenhouse gases is not very clear. Also, the indicator cannot be tuned to changes in the focus of policies. In contrast, (Social) Life Cycle Assessment can provide indicators relating to many aspects of policy, and therefore can also be tuned to changes in policy, but it is a very expensive tool and it is so complex that different LCA studies may deliver vastly different results for the same subject (cf. Figure 2).

Conceptual simplicity provides an indicator with robustness and reliability: different studies will reach similar conclusions, as there is little room for alternative interpretations. For the cost of evaluation, a critical point apart from conceptual simplicity is whether the computation of the indicator requires anything beyond readily available data. In regard to these two requirements, the best indicators are those that can be computed automatically

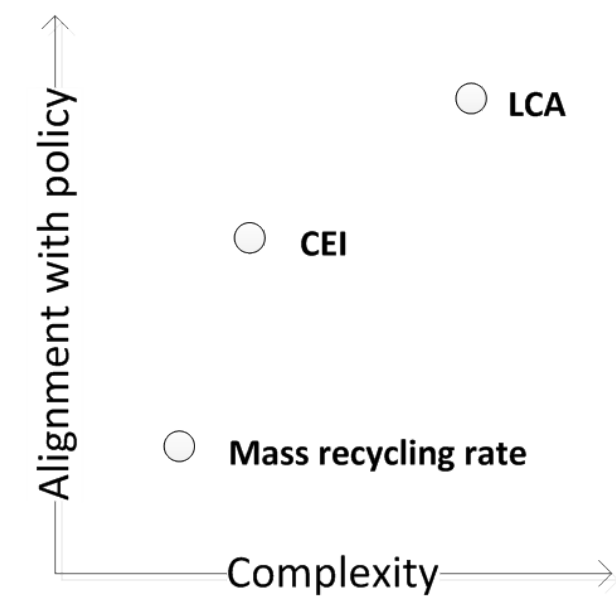

Figure 2. Alignment with policy vs complexity. 
(i.e., without issues requiring human interpretation) on the basis of data from standard, e.g. financial, reports.

Simple and cheap indicators typically point at a specific policy aspect, while they correlate, indirectly, with a number of other aspects. Mass recycling rates, for example, are directly related with the amount of waste that is deflected from landfills or incineration. Indirectly, mass recycling rates also correlate with the creation of jobs and the reduction of greenhouse gases. However, the relation between deflecting waste from landfills and creating jobs is so indirect that if creation of jobs becomes more important, at one point in time, than deflection from landfills, it makes sense to move to a different indicator.

The CEI proposed in this paper aims to be as simple as the mass recycling rate and better aligned with social, environmental and economic policies than the mass recycling rate while at the same moment, being simpler than LCA to be computed (cf. Figure 2).

\section{The Circular Economy Index}

Along with reuse and refurbish/remanufacturing, recycling plays an important role within the circular economy model and is often considered a cornerstone of a broader vision for the sustainability of a closed-loop society [6].

As material resources such as metal ores are becoming scarcer, there is an increasing incentive for upstream industries, such as smelters, to look for a secondary supply of resources from recycling activities. By strengthening the links between the primary resource supply sector and the recycling and waste management sector, both resource supply issues and waste management issues can be better addressed. Therefore indicators representing the recycling rate of materials and products have been used in the past. However, the definition of recycling rate varies considerably, mainly because both the numerator and denominator of the fraction that represent a recycling rate have been inconsistently chosen. The numerator often represents the amount of waste separated from waste streams for subsequent recycling, but usually the amount actually recycled is less than that separated because of the generation of residues in downstream recycling processes. This approach has brought about an inaccurate and somehow misleading indicator (the recycling rate) which might have contributed to wrong decision making and to poor innovation in the recycling industry.

The Circular Economy Index (CEI) proposed in this paper is the ratio of the material value produced by the recycler (market value) by the material value entering the recycling facility. In other words:

$$
\mathrm{CEI}=\frac{\text { Material value recycled from EOL product }(\mathrm{s})}{\text { Material value needed for }(\mathrm{re}-) \text { producing EOL product }(\mathrm{s})}
$$

Although several units to measure the resource efficiency are available (e.g. mass, volume, embedded energy, carbon footprint), the economic value (e.g. $€, \$$ ) has been selected because is aligns best with the present EU policies which aim at fostering social and environmental benefits for citizens. To avoid any inconsistency, the values should be measured as soon as EoL products are collected (at the beginning of Arrow 3 in Figure 1) and just before the materials enter the production process (at the end of Arrow 1in Figure 1).

The CEI solves some problems of LCA and mass recycling rates in a very elegant way. Unlike mass recycling rates, the CEI adjusts itself automatically if some specific material becomes more expensive because it is less available, e.g. as a consequence of strategic issues, or if a material becomes cheaper because of a very efficient recycling technology.

Unlike LCA's, the computation of the CEI does not become more complex because a material is produced in alternative ways (e.g. by the primary industry or by recycling) or at different qualities. Producers will always use the cheapest material that fit the required quality, and so the CEI will automatically adjust.

As recycling rate does, CEI is easy to be computed and it uses data which are easily made available. From management point of view it is easy to understand and compute it without doing complex calculations or calculations which use estimates to be performed. However from the scientific point of view, the recycling rate is not a suitable indicator because it is not directly related to what we want to achieve (it is not clear how it correlates to the societal impacts (economics, job creation, environment, strategic, ethical issues)). On the other hand, the LCA based thinking is rather good from the scientific point of view the, but from the management point of view is not feasible because it requires complex calculations which sometimes need estimate numbers to be performed.

While it won't be possible to enforce a law requiring that all companies should perform an LCA, it will be 
possible to do it with the CEI because it is easy to be interpreted and computed and does not require extra human resources to be done. These two points are extremely important for successful policies. We can only have successful policies if we have a driver (the index), if we can measure it, if it is clear to everybody what it means, and if it is related to what we want to achieve. Furthermore it should be noticed the need of policies which speed up circularity. Although current policies stimulate waste collection, most materials are not properly re-used or recycled (e.g. plastics).

To compute the CEI for a specific EoL product, it is necessary to know detailed information of the components and materials contained in each end of life (EOL) product entering the recycling facilities. Therefore an accurate accounting process taking into consideration the materials (with standards if available), mass, chemical composition and smallest dimension (e.g. a screw) is proposed.

An important aspect of the CEI is the possibility to compute it also at sector or company levels by making use of the financial data contained in the financial reports at company level or in the database of the institutions which collect data at national level (e.g. bureau of statistics, chamber of commerce, etc.).

\section{Experimental (KRI) and Financial (GVA) Calculation Methods}

To experimentally compute the CEI it is necessary to know detailed information of the components and materials contained in each end of life (EoL) product entering the recycling facilities. Therefore the development and demonstration of Key Recycling Info (KRI) system which takes into consideration the materials (with standards if available), mass, chemical composition and smallest dimension (e.g. a screw) is necessary. EOL products should be taken apart in all components and dismantled (i.e. a model of flat panel display, a model of washing machine, five regular plastic packaging). Each EOL's component should be disassembled and documented so that the precise number of indivisible components as well as amount of each material contained in the selected product goods is available and collected in the Key Recycling Info sheet. From this sheet the precise market value embedded in the EOL products can be calculated at any time.

Industry plays an important role for innovation and efficiency in a market economy and is particularly prone to generate value from scarce resources. It is generally accepted that without corporate support, society will not achieve environmental sustainability, as firms represent the productive resources of the economy [24]. Therefore an index that is easy to interpret and cheap to be computed using existing information is very important to make the green business case more appealing. This way industry will likely increase their contribution to minimize environmental challenges and pressures.

The Gross Value Added method takes into consideration the value of the materials contained in each functional component a product is made of. Although this information may be considered as confidential when the product is launched on the market, it is no longer the case after a predictable period of time (which depends from the specific consumer product characteristics). As soon as the product reaches its end of life and enters the recycling facilities, it will be possible to calculate the GVA generated by processing that product.

The GVA can be computed also using financial data. The general formula of GVA is the following:

GVA = Recycling firm revenues-non factor costs.

Recycling firm revenues include mainly revenues from selling secondary materials.

Non-factor costs for recycling companies include costs for energy and input materials.

Therefore the GVA of recycling companies consists mainly of the resource added value of the recycling activities.

The CEI will be the ratio of the GVA over the material input value (cf. Figure 3).

\section{How CEI Relates to Economic Social and Environmental Issues}

The CEI is linked to several targets we want to achieve in society (e.g. economic growth) and from management point of view requires data that can actually be easily generated (GVA). From the science point of view it relates to the societal and environmental impacts of economic growth.

Figure 4 shows how CEI correlates with the carbon footprint avoided by recycling.

From Figure 4 it is clear that the use of current recycling rate (based on mass) as an index to stimulate recycling is not as effective as the CEI. The graph shows that reclaiming material value from waste strongly correlates with reducing carbon footprint. For example if we suppose for convenience that a car is made of just four materials (steel, aluminum, copper and plastics), the current target recycling rate of $85 \%$ set by the European 


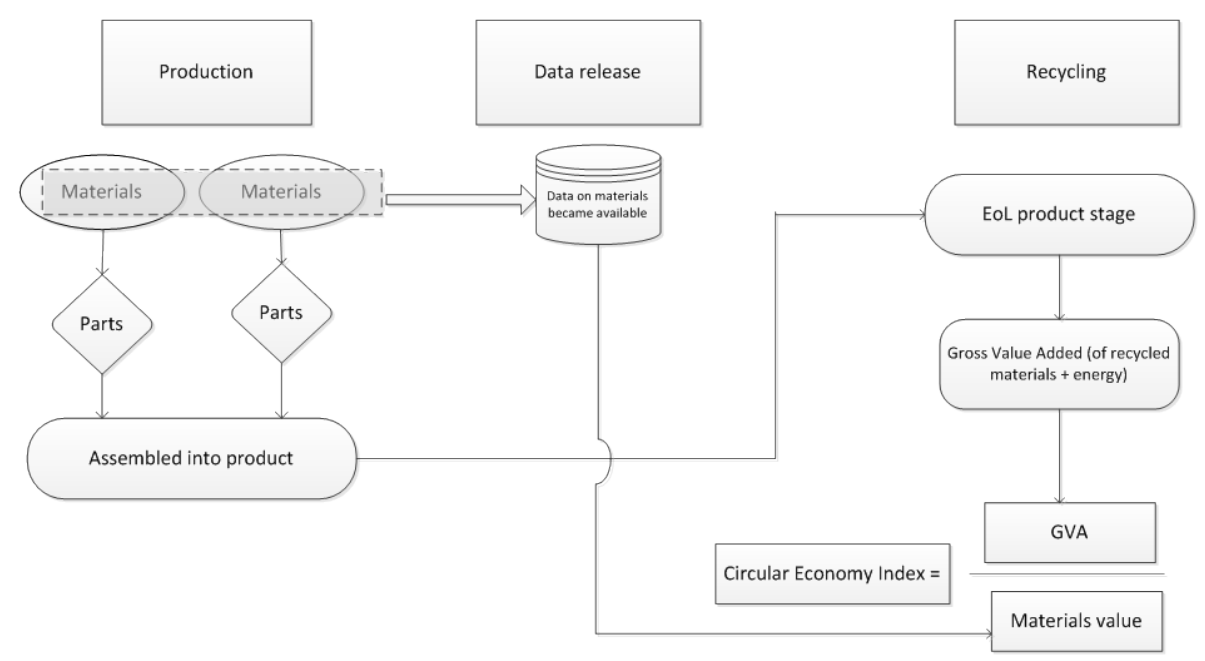

Figure 3. The circular economy index at EoL product level and at sector level.

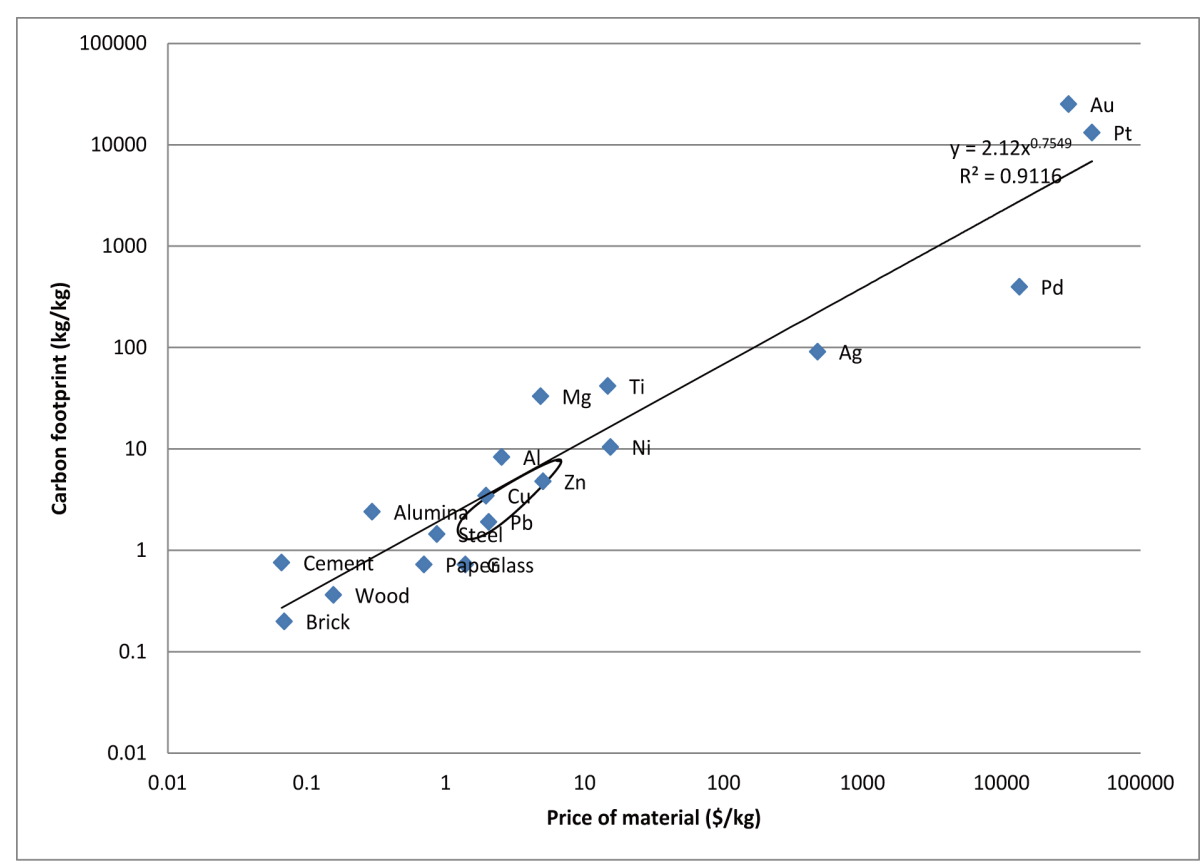

Figure 4. The carbon emission in kilograms of $\mathrm{CO}_{2}$ per kilogram of material produced versus the price of materials (data from [25]).

Commission directive [26], is driving recyclers to maximize the separation of steel rather than aluminum, copper or plastics. This is due to the available state of art technologies that can effectively separate steel scraps from the automotive shredder residues (ASR). However from Figure 4 appears that separating the more valuable $\mathrm{Al}$ and plastics materials provides considerable environmental benefits along with an economic one. Considering that recycling plastics from ASR require advanced technologies, if policy makers set the recycling target based on mass rather than on value (so that there will be no difference between a $\mathrm{kg}$ of steel and one of Al or plastics), the recycling industry will maximize steel recycling and will not develop new technologies. Therefore these policies do not foster the recycling of materials that can generate more revenues, create more jobs and have higher footprint than steel.

The following example will make the above point even more outstanding. If the composition of the car is the one presented in Table 1.

Three scenarios can be envisaged: 
Table 1. Car composition in kg.

\begin{tabular}{ccccc}
\hline Materials & Steel & Plastics & $\mathrm{Al}$ & $\mathrm{Cu}$ \\
\hline Mass $(\mathrm{kg})$ & 600 & 130 & 50 & 20 \\
\hline
\end{tabular}

1) Use of standard technology to extract $620 \mathrm{~kg}$ of steel contaminated by $\mathrm{Cu}$ from the ASR.

2) Use of advanced technology to extract $130 \mathrm{~kg}$ plastics plus $50 \mathrm{~kg} \mathrm{Al}$ from the ASR.

3) Use of advanced technology to separate steel from $\mathrm{Cu}$.

From the mass recycling rate point of view, the largest contribution is in Scenario 1 because the larger amount of material (low grade steel) is recycled from the EoL car $(620 \mathrm{~kg})$. However if we use a CEI approach, the separation of the $120 \mathrm{~kg}$ of plastics and the $50 \mathrm{~kg}$ of $\mathrm{Al}$, produces a higher value and at the same time, has a higher positive impact on the environment (cf. Figure 4). It is clear that the mass recycling rate approach provides a smaller incentive to valorize the plastics and $\mathrm{Al}$ contained in the ASR. This is even more evident looking at Scenario 3. In this case, the mass recycling rate approach produces no outcome at all. Therefore there is no driving force for separating steel from $\mathrm{Cu}$. On the other hand, the CEI approach encourages the separation of these metals because the value of $600 \mathrm{~kg}$ high grade steel and $20 \mathrm{~kg} \mathrm{Cu}$ is much higher than the $620 \mathrm{~kg}$ of low grade steel coming from Scenario 1. Therefore the use of the CEI approach is a driver for the use of innovative technologies, creates economic value and jobs and it has positive effects on the environment.

\section{Science and Policy Requirements}

Concerns about sustainable management of natural resources and efficient use of raw materials are growing worldwide. In particular materials and energy security. At the same time, the need to minimize environmental impact is more critical than ever. Against this background, many governments have increased efforts to promote deployment of resources efficient technologies that can strengthen resources security. This may stimulate an interest in innovative green technologies so that they are now a growing sector of the sustainable technology field.

Transforming the economy onto a resource-efficient path will bring increased competitiveness and new sources of growth and jobs through cost savings from improved efficiency, commercialisation of innovations and better management of resources over their whole life cycle. This requires policies that recognize the interdependencies between the economy, wellbeing and natural capital and seeks to remove barriers to improved resource efficiency, whilst providing a fair, flexible, predictable and coherent basis for business to operate [11].

In order for decision makers to be effective, they need robust and clear indicators that show the links between social, environmental and economic goals so that they can better understand how to achieve economic growth that is in harmony with the natural systems within which we live and work [27] [28].

Indicators can be used i) individually, ii) as part of a set, or iii) in the form of a composite index that combines individual indicator scores into a single number. Such a single aggregated number can be very useful in communicating information on general sustainability to the public and to decision makers [27]. Possible disadvantages are that the methods to achieve an aggregation are often subjective [29] [30] and that every index contains hidden assumptions and simplifications [31]. Therefore, such combined indicators need to be used judiciously. Farrell and Hart (1998) state that in many cases, indicators to measure sustainability are no more than combined lists of traditional economic, environmental and social indicators with the word 'sustainable' added to the title. Nevertheless, such combination is a first significant step because it recognizes that all three areas (economic, ecological and social) matter: sustainable development is a holistic concept and ideally one should strive to consider all three pillars of sustainability simultaneously [28]. Therefore, it is important that the development of indicators does not stop at this stage [27]. Economic and ecological analysis need to be combined [32] and one should concentrate on the interaction rather than on just the environment itself [33]. The advantage of aggregate indicators is that the information is presented in a format tailored to decision makers [33]-[35]. However, we need to be careful and informed about the way of aggregation, the uncertainties, the weights and the data source. Decision makers are too busy to deal with these details and the beauty of the aggregate indicator is the fact that it does the job for them [34]. But, no single indicator can possibly answer all questions and therefore multi-dimensional indicators can be needed [36] [37].

The advantage of the CEI proposed here is that it provides a clear indication of how good a recycling company is in valorizing the materials it processes and in combination with the KRI give environmental, technical and 
economic information which are useful to better perform LCA, MFA, I/O analysis, to design recycling processes and to predict the amount of stock-in-use materials.

Moreover the CEI and KRI may be used by policy makers to foster innovation by properly designing environmental standards. Such standards can trigger innovation that may partially or more than fully offset the costs of complying with them. Such "innovation offsets," [38], can not only lower the net cost of meeting environmental regulations, but can even lead to absolute advantages over firms in foreign countries not subject to similar regulations. Innovation offsets will be common because reducing pollution and increase resources efficiency is often coincident with improving the productivity with which resources are used. In short, firms can actually benefit from properly crafted environmental regulations that are more stringent (or are imposed earlier) than those faced by their competitors in other countries. By stimulating innovation, strict environmental regulations can actually enhance competitiveness.

\section{Conclusions}

In this paper, we argue that in order to move towards a more sustainable development, it is necessary to reclaim as much as possible material value from waste through effective recycling. To date this is not happening because the current indicators are not properly related to socio-economic goals. Therefore we propose a simple and robust indicator (the CEI) that is easy to be calculated and interpreted.

We show that the CEI is related to societal targets as well as the environmental and economic ones. Extracting value from EOL products brings about increased revenues (more jobs) and at the same time, decreases the impact on the environment.

The indicator we proposed fosters the use of innovative technologies to valorize the secondary resources contained in waste streams.

\section{References}

[1] Ellen Mac Arthur Foundation (2014) Toward the Circular Economy-Accelerating the Scale-Up across Global Supply Chains.

[2] European Commission (2014) Towards a Circular Economy: A Zero Waste Programme for Europe. Communication from the Commission to the European Parliament, the Council, the European Economic and Social Committee and the Committee of the Regions, COM(2014) 398 Final/2.

[3] Golder Europe EEIG (2004) Implementation of the Landfill Directive in the 15 Member States of the European Union, ENV.A.2/ETU/2004/0016.

[4] Hüther, M. (2010) Volkswirtschaftliche Bedeutung der Entsorgungs—und Rohstoffwirtschaft, Institut der Deutschen Wirtschaft Köln.

[5] European Parliament and Council Directive 94/62/EC, 1994, on Packaging and Packaging Waste.

[6] Gutowski, T.G., Allwood, J.M., Herrmann, C. and Sahni, S. (2013) A Global Assessment of Manufacturing: Economic Development, Energy Use, Carbon Emissions, and the Potential for Energy Efficiency and Materials Recycling. Annual Review of Environmental Resources, 38, 81-106. http://dx.doi.org/10.1146/annurev-environ-041112-110510

[7] Whitney, T. (2015) Conflict Minerals, Black Markets, and Transparency: The Legislative Background of Dodd-Frank Section 1502 and Its Historical Lessons. Journal of Human Rights, 14, 183-200. http://dx.doi.org/10.1080/14754835.2015.1021036

[8] UNEP (2011) Recycling Rates of Metals, A Status Report. United Nations Environmental Programme.

[9] EEA Report| No 8/2011, Earnings, Jobs and Innovation, the Role of Recycling in a Green Economy.

[10] Blake, M.K. and Hanson, S. (2005) Rethinking Innovation: Context and Gender. Environment and Planning A, 37, 681-701. http://dx.doi.org/10.1068/a3710

[11] European Commission (2011) Roadmap to a Resource Efficient Europe. Communication from the Commission to the European Parliament, the Council, the European Economic and Social Committee and the Committee of the Regions, COM(2011) 571 Final.

[12] EUROSTAT (2001) Economy-Wide Material Flow Accounts and Derived Indicators-A Methodological Guide. Office for Official Publications of the European Communities, Luxemburg.

[13] Ayres, R.U. (2008) Sustainability Economics: Where Do We Stand? Ecological Economics, 67, 281-310. http://dx.doi.org/10.1016/j.ecolecon.2007.12.009

[14] Ayres, R.U. and Kneese, A.V. (1969) Production, Consumption \& Externalities. American Economic Review, 59, 282- 
296.

[15] Gordon, R.B., Bertram, M. and Graedel, T.E. (2005) Metal Stock and Sustainability. Proceedings of the National Academy of Sciences of the United States of America, 103, 1209-1214.

[16] Ellen Mac Arthur Foundation (2014) Toward the Circular Economy-Economic and Business Rationale for an Accelerated Transition.

[17] Europe INNOVA (2012) Guide to Resource Efficiency in Manufacturing.

[18] Guinée, J.B., Gorrée, M., Heijungs, R., Huppes, G., Kleijn, R., de Koning, A., van Oers, L., Wegener Sleeswijk, A., Suh, S., Udo de Haes, H.A., de Bruijn, H., van Duin, R., Huijbregts, M.A.J., Lindeijer, E., Roorda, A.A.H., van der Ven, B.L. and Weidema, B.P., Eds. (2002) Handbook on Life Cycle Assessment. Operational Guide to the ISO Standards. Institute for Environmental Sciences. Leiden University, Leiden.

[19] Thomassen, M.A., Dolman, M.A., van Calker, K.J. and de Boer, I.J.M. (2009) Relating Life Cycle Assessment Indicators to Gross Value Added for Dutch Dairy Farms. Ecological Economics, 68, 2278-2284. http://dx.doi.org/10.1016/j.ecolecon.2009.02.011

[20] Wäger, P.A. and Hischier, R. (2015) Life Cycle Assessment of Post-Consumer Plastics Production from Waste Electrical and Electronic Equipment (WEEE) Treatment Residues in a Central European Plastics Recycling Plant. Science of the Total Environment, 529, 158-167. http://dx.doi.org/10.1016/j.scitotenv.2015.05.043

[21] Glavič, P. and Lukman, R. (2007) Review of Sustainability Terms and Their Definitions. Journal of Cleaner Production, 15, 1875-1885. http://dx.doi.org/10.1016/j.jclepro.2006.12.006

[22] Ness, B., Urbel-Piirsalu, E., Anderberg, S. and Olsson, L. (2007) Categorising Tools for Sustainability Assessment. Ecological Economics, 60, 498-508. http://dx.doi.org/10.1016/j.ecolecon.2006.07.023

[23] Moriguchi, Y. (2007) Material Flow Indicators to Measure Progress toward a Sound Material-Cycle Society. Waste Management, 9, 112-120. http://dx.doi.org/10.1007/s10163-007-0182-0

[24] Bansal, P. (2002) The Corporate Challenges of Sustainable Development. Academy of Management Executive, 16, 122-131. http://dx.doi.org/10.5465/AME.2002.7173572

[25] Gutowski, T.G., Sahni, S., Allwood, J.M., Ashby, M.F. and Worrell, E. (2013) The Energy Required to Produce Materials: Constraints on Energy-Intensity Improvements, Parameters of Demand. Philosophical Transactions of the Royal Society A, 371, Article ID: 20120003. http://dx.doi.org/10.1098/rsta.2012.0003

[26] European Commission (2000) Directive 2000/53/EC of the European Parliament and of the Council on End-of Life Vehicles.

[27] Farrell, A. and Hart, M. (1998) What Does Sustainability Really Mean? The Search for Useful Indicators. Environment, 40, 4-9. http://dx.doi.org/10.1080/00139159809605096

[28] Van Passel, S., Nevensa, F., Mathijsb, E. and Van Huylenbroeck, G. (2007) Measuring Farm Sustainability and Explaining Differences in Sustainable Efficiency. Ecological Economics, 62, 149-161. http://dx.doi.org/10.1016/j.ecolecon.2006.06.008

[29] Becker, B. (1997) Sustainability Assessment: A Review of Values, Concepts and Methodological Approaches, Issues in Agriculture. CGIAR World Bank, 10, 1-63.

[30] Hueting, R. and Reijnders, L. (2004) Broad Sustainability Contra Sustainability: The Proper Construction of Sustainability Indicators. Ecological Economics, 50, 249-260. http://dx.doi.org/10.1016/j.ecolecon.2004.03.031

[31] Hanley, N., Moffatt, I., Faichney, R. and Wilson, M. (1999) Measuring Sustainability: A Time Series of Alternative Indicators for Scotland. Ecological Economics, 28, 55-73. http://dx.doi.org/10.1016/S0921-8009(98)00027-5

[32] Kaufmann, R.K. and Cleveland, C.J. (1995) Measuring Sustainability: Needed-An Interdisciplinary Approach to an Interdisciplinary Concept. Ecological Economics, 15, 109-112. http://dx.doi.org/10.1016/0921-8009(95)00062-3

[33] Jollands, N., Lermit, J. and Patterson, M. (2003) The Usefulness of Aggregate Indicators in Policy Making and Evaluation: A Discussion with Application to Eco-Efficiency Indicators in New Zealand. ISEE Working Paper.

[34] Constanza, R. (2000) The Dynamics of the Ecological Footprint Concept. Ecological Economics, 32, 341-345.

[35] Azapagic, A. (2004) Developing a Framework for Sustainable Development Indicators for the Mining and Minerals Industry. Journal of Cleaner Production, 12, 639-662. http://dx.doi.org/10.1016/S0959-6526(03)00075-1

[36] Opschoor, H. (2000) The Ecological Footprint: Measuring Rod or Metaphor. Ecological Economics, 32, 363-365.

[37] Veleva, V. and Ellenbecker, M. (2000) A Proposal for Measuring Business Sustainability: Addressing Shortcomings in Existing Frameworks. Greener Management International, 31, 101-120.

[38] Porter, M.E. and van der Linde, C. (1995) Toward a New Conception of the Environment-Competitiveness Relationship. The Journal of Economic Perspectives, 9, 97-118. http://dx.doi.org/10.1257/jep.9.4.97 